\title{
高速公路 AC-13C 上面层应用闪长岩集料的材料性能分析及研究
}

\section{Analysis and Research on material properties of diorite aggregate applied in upper layer of AC-13C Expressway}

\author{
汪继平 $^{1}$ 李继业 $^{2}$ 谭强 $^{2}$ \\ Jiping Wang Jiye Li Qiang Tan \\ 1 广西桂东高速公路有限公司 中国·南宁 530000；2 中交一公局第四工程有限公司 中国·南宁 530033 \\ 1 Guangxi Guidong Expressway Co., Ltd., Nanning, 530000, China \\ 2 The Fourth Engineering Co., Ltd. of CCCC First Highway Engineering Co., Ltd., Nanning, 530033, China
}

摘 要: 目前, 闪长岩集料在广州、深圳及江苏地区有少量应用, 使用效果较好, 广西区在贵港市附近的一条市政路上面 层进行了 $2 \mathrm{~km}$ 的试验段施工，但未大面积使用，近年，在国家倡导的“一带一路”及广西区内“县县通高速”发展战略引 领下, 广西作为一带一路的桥头堡城市, 境内辉绿岩和玄武岩集料用量激增, 已无法满足目前的需要, 急需寻找可以用于 励青上面层的第三种材料。

\begin{abstract}
At present, diorite aggregate in Guangzhou, Shenzhen and Jiangsu area has a small amount of application, the use effect is good, guangxi district in Guigang City near a municipal road aboveIn recent years, it has been introduced in the development strategy of "One Belt And One Road" advocated by the state and "county to county to high speed" in Guangxi region Under the leadership of Guangxi, as the bridgehead city of One Belt And One Road, the increase of diabase and basalt aggregate in the territory has been unable to meet the current needs, and it is urgently needed to find suitable materials for use The third material in the overlay of bitumen.
\end{abstract}

关键词：闪长岩；酸碱性；集料指标；压碎值

Key words: diorite; Acid and alkali; Aggregate index; Crush value

DOI: 10.36012 /etr.v2i9.2651

\section{引言}

广西梧州至柳州高速公路路面某标段，全长 $43.5 \mathrm{~km}$ 。 沥青上面层采用 $\mathrm{AC}-13 \mathrm{C}$ 结构型式, 工程量约 106 万 $\mathrm{m}^{2}$, 混合料数量约为 10.9 万 $\mathrm{t}$ 。原设计 $\mathrm{AC}-13 \mathrm{C}$ 改性沥青混凝土 上面层材料要求使用玄武岩或门长岩集料, 但因项目附近地 区玄武岩、辉绿岩材料稀缺, 项目经过多方调查、取样, 通 过大量的可行性研究, 确定了使用闪长岩代替辉绿岩、玄武 岩用于沥青上面层的方案。

本文旨在对闪长岩的原材料性能进行分析, 为闪长岩 用于上面层的相关配合比试验、平行验证试验做好基础数据 收集及技术准备工作。

\section{1 材料选用背景}

本项目地处广西区梧州市藤县境内, 境内玄武岩或辉 绿岩石料稀缺, 需要从贵港或田东远运, 运输距离较长, 运 输费用高, 且存在涨价、材料供应不足的风险, 影响整条高 速公路的通车目标。项目进场后，组织人员对附近的石料场
进行了详细调查及取样, 发现藤县境内储存着大量的闪长 岩, 取样送检后, 其相关技术指标满足上面层用原材的要求。

对闪长岩用于沥青上面层的使用情况进行调查发现，闪长 岩在广东、江苏等省份有少量应用。本项目通过严格的材料选 型, 并结合其他省份高速公路成功案例的经验, 进行对比分析, 形成了一整套系统、完善的可行性研究资料，其各项性能指标 不低于辉绿岩及玄武岩, 建议使用闪长岩代替辉绿岩及玄武岩 用于上面层, 最终获得了各方的认可, 解决了料源紧缺问题、 材料周转带来的工期压力问题，降低项目施工成本。

\section{2 闪长岩基本情况}

闪长岩为全晶质中性深成岩的代表岩石, 其化学成分 介于酸性、基性岩之间， $\mathrm{SiO}_{2}$ 含量 $52 \% \sim 65 \%$ ，结构多半 为半自形粒状, 斜长石晶形一般较好, 呈板柱状, 矿物颗粒 均匀, 多为块状构造。闪长岩为致密状构造, 硬度、强度等 物理力学性能指标较高, 化学性质也比较稳定, 因此, 闪长 岩类集料具有良好的上面层用材料的各种性质。

【作者简介】汪继平 ( 1975$)$ ，男，大学本科，高级工程师，从事施工技术管理研究。 


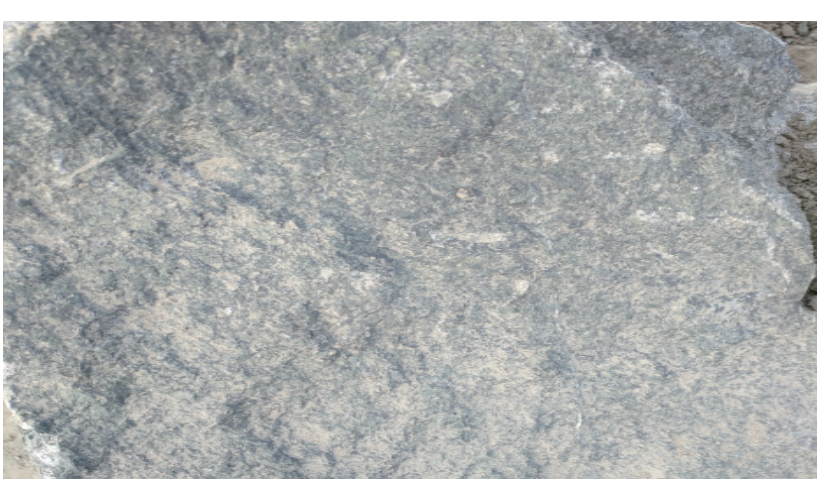

蚀变石英闪长岩

在一般情况下, 辉绿岩属于碱性石料, 与励青的粘附性 最好, 玄武岩属于酸性石料, 与沥青的粘附性较差, 由于闪

长岩在广西地区作为上面层所用集料应用较少, 需要对闪长 岩的母岩强度、酸碱性、各项集料性能指标进行试验检测分析。

闪长岩很少组成独立的岩体, 闪长岩的岩性较杂, 其 表面附着一些类似石英状的侵入体，各个地方的闪长岩岩质 差别较大, 生产时, 需要针对性的进行生产线的配置、破碎 方式选择及破碎机械选型。

\section{3 岩石强度测定}

为了确定该项目拟使用的广西梧州市藤县杉花根石场 的母岩强度, 项目部 (其他标段后来也送检) 多次在石场料 源地取岩石送至广西交通科学研究院有限公司、广西交通规 划勘测设计研究院有限公司进行饱水抗压强度检测, 检测结 果如下:

闪长岩强度检测情况

\begin{tabular}{ccccc}
\hline 项目 & 检测单位 & 样品编号 & 检测结果 $(\mathrm{MPa})$ & 说明 \\
\hline NO.A & 广西交通科学研究院有限公司 & 2016-MA01297-0171 & 179.8 \\
NO.A & 广西交通科学研究院有限公司 & 2017-MA0037-0044 & 140.8 \\
NO.A & 广西交通科学研究院有限公司 & 2017-MA0037-0045 & 107.9 \\
NO.A & 广西交通规划勘测设计研究院有限公司 & SL-2017-0212 & 95.9 \\
NO.A & 广西交通规划勘测设计研究院有限公司 & SL-2017-0213 & 111.8 \\
NO.B & 广西交通科学研究院有限公司 & 2017-MA0037-0046 & 98.9 & \\
\hline
\end{tabular}

由上表可知, 该闪长岩集料料源地的母岩强度与母岩 的节理、成型有较大关系, 强度的波动较大, 为保证生产 的集料材料稳定，应挑选大块、成型好、风化软弱石料少的 毛石进行材料的生产，料场增设水洗整形设备，确保材料的 洁净。

项目部结合业主、路面咨询单位及以往项目的经验等, 对料场的加工生产线做出了要求，并对影响集料粒径及和级 配的因素进行严格进行控制 :

(1)篮网尺寸：碎石场采用 $4 * 4 \mathrm{~mm} 、 6 * 6 \mathrm{~mm} 、 11 * 11 \mathrm{~mm}$ 、 $16 * 16 \mathrm{~mm}$ 集料加工筛网筛孔尺寸 ;

(2)耖网倾角 : 集料加工的振动筛篮板倾角控制在 $24^{\circ}$ 。

(3)破碎工艺: 采用反击破 + 圆锥破 + 冲击破 + 整形机 的多级破碎工艺。

\section{4 岩石岩性鉴定}

为了确定拟使用的藤县杉花根石场的岩石类别及酸碱 性，在石场料源地取材料送至国土资源部南宁矿产资源监督 检测中心、广西壮族自治区地质矿产测试研究中心进行岩石 类别判定及岩石二氧华硅含量 (委托路面咨询单位送检) 检 测, 检测结果如下:
室内定名及岩石成分表

室内定名（鉴定结果）：蚀变石英闪长岩 结构构造: 他型粒状变晶结构、块状结构 矿物成份 (\%):

\begin{tabular}{|l|l|l|l|l|l|}
\hline 斜长石 & 55 & 墨约帘石 & $<1$ & 锆石 & $<1$ \\
\hline 阳起石 & 3 & 绢云母 & 2 & 不透明矿物 & 1 \\
\hline 绿泥石 & 5 & 普通角门岩 & 21 & 黑云母 & $\leq 1$ \\
\hline 石英 & 10 & 磷灰石 & $\leq 1$ & & \\
\hline 绿穴石 & 1 & 榍石及白钛石 & $<1$ & &
\end{tabular}
简要描述: 普通角闪石呈他型粒状、板柱状; 石英呈他型粒状; 它们不均匀地分布于斜长石粒间。细微质点状的䵢窝石, 它们或 聚集或分散不均匀地交代原石的各种矿物（主要是暗色矿物）, 其余微量矿物零星可见。

\begin{tabular}{ccc}
\multicolumn{3}{c}{ 二氧化硅含量测定 } \\
\hline 送检日期 & 检测项目 & 检测结果 $(\%)$ \\
\hline 2016.12 .15 & $\mathrm{w}\left(\mathrm{SiO}_{2}\right)$ & 53.16 \\
2017.8 .16 & $\mathrm{w}\left(\mathrm{SiO}_{2}\right)$ & 52.06 \\
\hline
\end{tabular}

从以上两个表可知, 藤县杉花根石场料源地取取样岩石 定性为蚀变石英闪长岩, 根据《道路建筑材料》李立寒版本 中关于道路工程集料酸碱性的定义: $\mathrm{SiO}_{2}>65 \%$ 者称为酸性 岩, 代表性岩石有花岗岩和石英岩: $\mathrm{SiO}_{2}$ 含量在 $52 \sim 66 \%$ 者称为中性岩，代表性岩石为辉绿岩和闪长岩; $\mathrm{SiO}_{2}<52 \%$ 
者称为碱性岩, 代表性岩石为石灰岩和玄武岩。根据检测结 果可知 : 取样岩石的酸碱性为中性。

根据沥青与集料的化学反应理论 : 碱性石料表面存在 碱性活性中心，容易与沥青中的酸性成分发生化学反应，生 成不溶于水的化合物, 因此粘附性好; 酸性石料缺乏碱性活 性中心, 故较少发生化学反应, 沥青与集料之间只有机械力 的作用, 因此酸性石料与沥青粘附性较差, 闪长岩介于两者 之间, 因此粘附性较好。

\section{5 集料指标检测情况}

在广西梧州市藤县杉花根石场闪长岩集料加工工 地取生产的集料送样至广西交科院，按照业主桂东发 【2016】193号《广西桂东高速公路有限公司关于印发 梧州至柳州高速公路沥青混合料配合比设计及审批实施 细则的通知》文件要求中、上面层主要性能指标进行检 测，路面 B 标及路面咨询单位也在同一个石场平行取样 送检，加大试验频率，以验证材料的使用性能，检测结果 如下:

闪长岩集料性能指标检测结果

\begin{tabular}{|c|c|c|c|c|c|}
\hline 检验项目 & $\begin{array}{l}\text { 指标要求 } \\
\text { (文件) }\end{array}$ & $\begin{array}{c}\text { № A 合同段委托 } \\
\text { 交科院检验 }\end{array}$ & $\begin{array}{c}\text { № B 合同段委托 } \\
\text { 交科院检验 }\end{array}$ & $\begin{array}{l}\text { 交投科技委托 } \\
\text { 交科院检验 }\end{array}$ & $\begin{array}{l}\text { 广西交投科技 } \\
\text { 自行验证 }\end{array}$ \\
\hline 石料压碎值 (\%) & $\leq 20$ & 11.2 & 13.5 & 13.4 & 13.9 \\
\hline 洛杉矶磨耗损失 (\%) & $\leq 25$ & 18.9 & 9.9 & 12.2 & 17.9 \\
\hline 粗集料对沥青的粘附性 (潮湿区) & $\geq 5$ 级 & 5 级 & 5 级 & 5 级 & 5 级 \\
\hline 石料磨光值 (PSV)( 潮湿区 ) & $\geq 42$ & 45 & 45 & 43 & 44 \\
\hline 表观相对密度 (t/m³) & 2.6 & 2.866 & $2.856 、 2.848 、 2.859$ & $2.873 、 2.867 、 2.885$ & 2.853 \\
\hline 吸水率 (\%) & 2 & 0.48 & $0.72 、 0.82$ & $0.74 、 0.82 、 1.0$ & 0.58 \\
\hline 坚固性 (\%) & $\leq 12$ & 0 & $0 、 1$ & 0 & \\
\hline 针片状颗粒含量 (\%) & $\leq 12$ & l & 9.1 & 5.3 & $9 、 3.1$ \\
\hline 水洗法＜0.075mm 颗粒含量 $(\%)$ & $\leq 1$ & / & $0.2 、 0.3$ & $0.4 、 0.3$ & $0.38 、 0.58 、 0.89$ \\
\hline 软石含量 $(\%)$ & $\leq 1$ & l & 0 & $0.1 、 0$ & $0.7 、 0.8$ \\
\hline
\end{tabular}

10-15mm 闪长岩材料级配情况

\begin{tabular}{|c|c|c|c|c|c|c|c|c|c|c|c|}
\hline \multirow{2}{*}{\multicolumn{2}{|c|}{ 粒径（ mm） }} & \multicolumn{10}{|c|}{ 通过下列筛孔（ mm）的质量百分率（\%) } \\
\hline & & \multicolumn{2}{|c|}{16} & \multicolumn{2}{|c|}{13.2} & 9.5 & \multicolumn{3}{|c|}{4.75} & \multicolumn{2}{|c|}{2.36} \\
\hline \multicolumn{2}{|c|}{ 颗粒级配 } & \multicolumn{2}{|c|}{100} & \multicolumn{2}{|c|}{91.2} & 1.0 & \multicolumn{3}{|c|}{0.3} & \multicolumn{2}{|c|}{--} \\
\hline \multicolumn{2}{|c|}{ 级配上限 } & \multicolumn{2}{|c|}{100} & \multicolumn{2}{|c|}{100} & 15 & \multicolumn{3}{|c|}{5} & \multicolumn{2}{|c|}{--} \\
\hline \multicolumn{2}{|c|}{ 级配下限 } & \multicolumn{2}{|c|}{100} & \multicolumn{2}{|c|}{90} & 0 & & \multicolumn{2}{|c|}{0} & \multicolumn{2}{|c|}{--} \\
\hline \multicolumn{6}{|c|}{ 5-10mm 闪长岩材料级配情况 } & \multicolumn{6}{|c|}{ 3-5mm 闪长岩材料级配情况 } \\
\hline \multirow{2}{*}{ 粒径（mm） } & \multicolumn{5}{|c|}{ 通过下列籂孔 $(\mathrm{mm})$ 的质量百分率 ( \% ) } & \multirow{2}{*}{ 粒径 $(\mathrm{mm})$} & \multicolumn{5}{|c|}{ 通过下列䇻孔（ mm）的质量百分率（\%) } \\
\hline & 13.2 & 9.5 & 4.75 & 2.36 & 0.6 & & 9.5 & 4.75 & 2.36 & 0.6 & 0.075 \\
\hline 颗粒级配 & 100 & 91.3 & 2.5 & 0.2 & -- & 颗粒级配 & 100 & 90.4 & 0.9 & 0.3 & -- \\
\hline 级配上限 & 100 & 100 & 15 & 5 & -- & 级配上限 & 100 & 100 & 15 & 5 & -- \\
\hline 级配下限 & 100 & 90 & 0 & 0 & -- & 级配下限 & 100 & 90 & 0 & 0 & -- \\
\hline
\end{tabular}


从以上四个表中的数据来看, 所检材料的各项性能指 标均满足规范及业主的文件要求, 因此, 可以判定该石场生 产的闪长岩材料可以用于沥青上面层的施工。

\section{6 高温压碎值检测情况}

闪长岩石料场的 10-15 mm 档集料经过高温加热（设定 温度 $200^{\circ} \mathrm{C}$ ) 后, 取样对石料的两个指标进行检测, 检测结 果如下:

\begin{tabular}{ccc}
\hline 检验项目 & 指标要求 $($ 文件 $)$ & 检测结果 \\
\hline 石料压碎值 $(\%)$ & $\leq 20$ & 12.7 \\
洛杉矶磨耗损失 $(\%)$ & $\leq 25$ & 20.6 \\
\hline
\end{tabular}

从表中数据可以看出, 集料经过高温加热后, 其压碎 值及洛杉矶磨耗损失两个指标与未加热前变化不大, 因此材 料的高温加热后稳定性较好, 不会因施工过程中通过沥青站 高温加热后材料压碎值发生较大变化, 进而引起混合料质量 的降低。

\section{7 应用前景}

通过对闪长岩集料相关的试验检测数据进行完善, 实现 了“四新技术” 的有效应用, 各项技术经济指标不低于辉绿 岩、玄武岩, 有利的推广了闪长岩在沥青上面层的应用发展, 对今后类似路面工程施工具有重要的参考意义。同时, 进一 步肯定了闪长岩在广西地区的优越性能，对沥青路面的发展 起到了较好的推动作用, 符合国家可持续发展战略思路, 可 以推动行业科技创新, 符合可持续发展、绿色施工的行业需 求，具有良好的推广应用价值，就项目而言，节省的费用占 总的材料费用的 $26.42 \%$ ，经济效益显著。

\section{8 小结}

从闪长岩的岩性判定、强度试验、酸碱度检测到集料 的各相关指标试验结果来看, 闪长岩具备用于 $\mathrm{AC}-13 \mathrm{C}$ 改性 沥青上面的条件，具有不弱于辉绿岩、玄武岩的集料特性, 在加工过程中, 对母材进行挑选, 剔除软弱岩层, 以保证集 料的质量。

在项目的研究过程, 也发现了其存在的一些问题, 需 要进一步深入研究与解决, 使用过程中, 采取一定的 措施：

(1) 闪长岩的岩性较杂, 其表面附着一些类似石英状 的侵入体, 项目单独切割侵入体进行强度试验, 其强度 较高, 与闪长岩本体相当, 但该侵入体对沥青粘附性的影 响, 需要采用微观结构进行分析, 项目尚未达到该分析 条件。

(2) 闪长岩大多呈中性 酸性, 经过室内、室外试验, 包括外委试验表明, 不采取抗剥离措施的闪长岩上面层与采 取抗剥离措施的闪长岩各项指标差别甚微, 但对其通车后的 而久性缺乏数据分析, 需要长达 $2 \sim 3$ 年时间进行现场分析, 才能得到数据。

\section{参考文献}

[1] 《梧州至柳州高速公路两阶段施工图设计（K0+000 K43+542.585）（路面工程）》(陕西省交通规划设计研究院, 2016.6)

[2] 《公路沥青路面施工技术规范》（JTG F40-2004）

[3] 《公路沥青路面施工技术规范实施手册》（JTG F40-2004）

[4] 《广西桂东高速公路有限公司关于印发梧州至柳州高速公路㲽 青混合料配合比设计及审批实施细则的通知》(桂东发【2016 】 193 号) 